\title{
Epidemiological Profile of Gastric Adenocarcinoma in Morocco: Evolution and Risk Factors
}

\author{
Abdellah Ben Khali, \\ Laboratory of Genetics and Biometry, Faculty of Sciences, \\ University Ibn Tofail, Kenitra, Morocco \\ Houria Chahed Ouazzani, \\ University Hospital Center, Ibn Sina, \\ Hepato-Gastroenterology Department, Rabat, Morocco \\ Abdelmajid Soulaymani, \\ Ali Quyou, \\ Laboratory of Genetics and Biometry, Faculty of Sciences, \\ University Ibn Tofail, Kenitra, Morocco
}

\begin{abstract}
Background: Gastric cancer (GC) remains a public health issue despite the global incidence decrease over the last decades. GC is the third leading cause of cancer-related death worldwide and it is still of poor prognosis due to its late detection. This paper focuses on determining the sociodemographic and progressive characteristics of patients who presented gastric adenocarcinoma in the absence or in the presence of the bacterium Helicobacter pylori at the service of Hepato-Gastroenterology at the University Hospital of Rabat in Morocco. Methods: To evaluate the epidemiological characteristics of gastric adenocarcinoma in the absence or in the presence of the bacterium Helicobacter pylori, a retrospective study was conducted on cases admitted at the Hepato-Gastroenterology department (University Hospital, Avicene Rabat) between 2000 and 2010 to support gastric adenocarcinoma. Results: 240 cases of GC were recorded with an average of 22 cases per year, which represents $77 \%$ of all gastric cancers identified. Male gender is most affected. The frequency of appearance of ADK in the absence of the bacterium $\mathrm{Hp}$ is $82 \%$ (196 cases). It is $18 \%$ (44 cases) in the presence of $\mathrm{Hp}$. During the study period, 99 deaths were recorded: 81 cases in the presence of the bacterium Helicobacter pylori, 18 cases of death in the absence of $\mathrm{Hp}$. The lethality rate was higher in the male sex, either in the presence or absence of $\mathrm{Hp}$. Conclusions: Management of GC additionally to early diagnosis represents effective preventive and therapeutic methods of GC.
\end{abstract}


Keywords: Epidemiology, Gastric adenocarcinoma, Retrospective, Risk Factors

\section{Introduction}

Gastric cancer (GC) remains a public health issue despite the global decrease in the incidence over the last decades. Approximately one million of new cases were diagnosed (6.8\% of all cancers), making this digestive neoplasia the fifth most common malignancy and the third leading cause of cancer related-death in both genders worldwide (8.8\% of the total) (Bachir et al., 2018). The risk is particularly higher in Eastern Asia where half of the world total occurs mainly in China and Japan. Although the African continent is considered as a low incidence area, 13,216 new cases of stomach cancer were diagnosed and 12,000 cases of death were recorded in 2012 (Ferlay et al., 2012).

The most common histologic entity of GC is adenocarcinoma, accounting for $90 \%$ of all stomach tumors (Carl-McGrath et al., 2008). Sixty percent to Seventy percent of GCs represent the final step of mucosal precancerous inflammatory process induced by Helicobacter pylori (HP) infection (Malfertheiner). The pre-neoplastic cascade is initiated by atrophic chronic gastritis (ACG) which may persist and advance to intestinal metaplasia when compared to dysplasia. ACG and IM are considered as reversible steps regressing by the bacterium eradication (Carl-McGrath, 2014; Correa \& Piazuelo, 2013). Thus, this paper focuses on determining the sociodemographic and progressive characteristics of patients who presented gastric adenocarcinoma in the absence or in the presence of the bacterium Helicobacter pylori.

\section{Materials and Methods}

This is a descriptive retrospective study, during the period 2000 and 2010, which was conducted based on the records of patients in which their biopsies made during the examination of their stomachs by fibroscopy in the Department were consulted of Hepato-Gastroenterology at the University Hospital Center in Rabat, Morocco.

The statistical methodology was based on two axes:

- Descriptive Statistics: This involves the disengagement of frequencies and characteristics of each parameter studied. The results are expressed in raw values for the qualitative variables and in means \pm error of the mean for the quantitative variables.

- Analytical Statistics: The $\chi^{2}$ test and the reduced gap calculation $(\varepsilon)$ are used to determine whether a difference between some variables is significant. The calculation of the odds ratio (OR) informs us about the 
liaison of the various factors with the evolution of the adenocarcinomatous patients. On the other hand, we detected the degree of association between the location of gastric cancer and the presence or absence of Helicobacter pylori (Hp) bacteria.

\section{Results}

During the study period, we collected 240 cases of gastric adenocarcinomas in the Hepato-Gastroenterology Department of Ibn Sina Hospital, Rabat Medicine Service B in Morocco. The average annual number of cases recorded was 22 cases per year, which represents $77 \%$ of all gastric cancers recorded. The frequency of appearance of ADK in the absence of the Hp bacterium shows that the years, 2001, 2008 and 2010, are the highest with 25, 28 and 25 cases respectively. This, however, is contrary to the year 2002 which reported too few with only 5 cases (Figure 1).

During the same study period, a total of 44 cases of Hp-associated ADK were recorded at the rate of $18 \%$. The temporal distribution during collection years shows high peaks and low peaks (Figure 1).

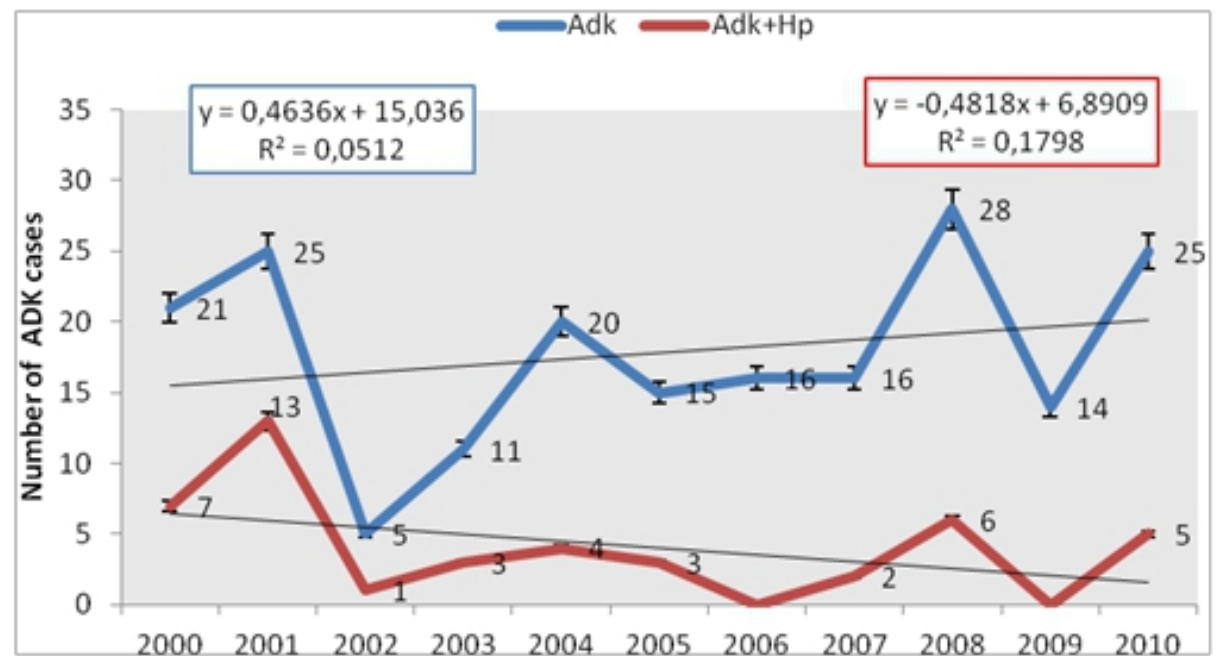

Figure 1. Temporal evolution of ADKs

According to the years of the 240 cases, 99 cases died ( $41 \%$ of the total patients). The average annual number of deaths is $9 \pm 0.94$ cases per year, with extremes ranging from 1 to 16 deaths. Figure 2 illustrates the annual distribution of the number of deaths of ADK in the presence (81 cases of death) and in the absence of the bacterium Helicobacter pylori (18 cases of death). 


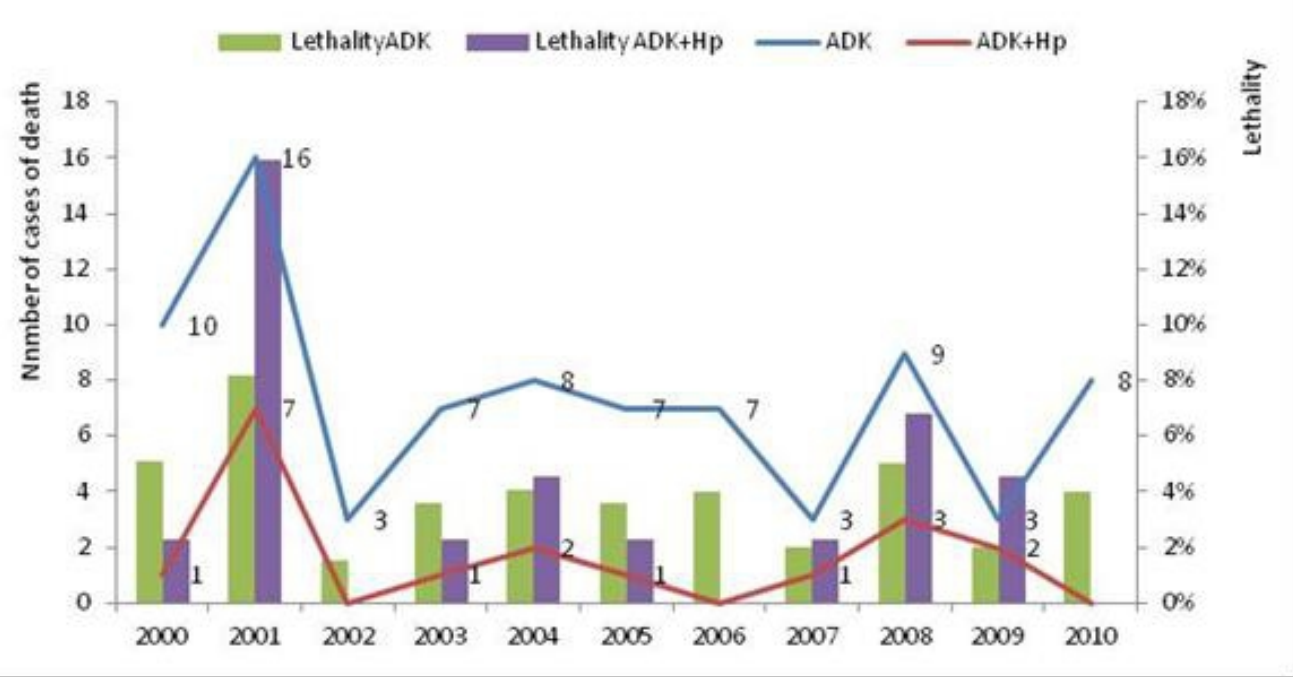

Figure 2. Annual distribution of deaths and case lethality rate

Furthermore, the distribution of cases of ADK deaths, not associated with Helicobacter pylori infection by sex, shows that 48 cases of death were male (59\%) and 33 cases $(41 \%)$ were female (Table 1) with a sex ratio (M/F) of $1.2(\chi 2=2.78, p=0.09)$. The highest case lethality rate was observed in males at $24 \%$, compared with $17 \%$ for females. The difference is not significant between the two sexes in terms of lethality $(\varepsilon=1.2)$.

Similarly for patients who developed an ADK associated with Helicobacter pylori infection, it was shown that 10 deceased cases are male with a frequency of $55 \%$ and 8 of them are female which is $45 \%\left(\chi^{2}=0.22 ;=\right.$ $0.6)$. Similarly, the case lethality rate is higher in the male sex with $23 \%$ compared to $18 \%$ in the female sex. The difference is not significant $(\varepsilon=0.26)$ in terms of lethality between the two sexes.

Indeed, the highest frequency of patients who have died from this type of cancer is aged 60 to 79, either in the absence or in the presence of the bacterium Helicobacter pylori with a case-fatality rate of $28 \%$ ( $n=68$ cases). This was followed by the 50-59 age group, with a case-lethality rate of 9\% (n $=21$ cases), and then the age of 80 or older with a case-fatality rate of $4 \%$ (n $=10$ cases) (Table 1$)$.

Table 1. Epidemiological characteristics of deceased patients

\begin{tabular}{ccccc}
\hline Variable & ADK & ADK+Hp & Lethality ADK (\%) & Lethality ADK+Hp(\%) \\
\hline Gender & & & & 18 \\
\hline Female & 23 & 8 & 12 & 23 \\
Male & 58 & 10 & 30 & \\
\hline Total & $\mathbf{8 1}$ & $\mathbf{1 8}$ & & 20 \\
\hline Age group & & & & 18
\end{tabular}




\begin{tabular}{ccccc}
{$[70-80[$} & 28 & 6 & 14 & 14 \\
$>=80$ & 10 & - & 5 & - \\
\hline Total & $\mathbf{8 1}$ & $\mathbf{1 8}$ & & \\
\hline
\end{tabular}

Furthermore, we studied the effect of certain factors on the evolution of patients. The independence test $\chi 2$ and the Odds Ratio are calculated to identify the risk factors that would have affected the progression of the state of health of adenocarcinomatous patients in our series. Table 2 mentions the analysis of the association between evolution and the socio-epidemiological and evolutionary parameters that were studied.

Table 2. Risk factors that influence the evolution of patients

\begin{tabular}{|c|c|c|c|c|c|c|}
\hline Associated factor & Favorable & Death & $\chi^{2}$ to 1 ddl & $\mathbf{p}$ & OR & CI to $95 \%$ \\
\hline \multicolumn{7}{|l|}{ Sex } \\
\hline Female & 66 & 41 & 0,69 & NS & 0,8 & $0,48-1,34$ \\
\hline Male & 75 & 58 & & & 1,24 & $0,74-2,08$ \\
\hline Total & 141 & 99 & & & & \\
\hline \multicolumn{7}{|l|}{ Age group (Years) } \\
\hline$[10-20[$ & - & & & & & \\
\hline$[20-30[$ & 6 & - & & & - & \\
\hline$[30-40[$ & 14 & - & & & - & \\
\hline$[40-50[$ & 37 & - & & & - & \\
\hline$[50-60[$ & 37 & 18 & 2,14 & NS & 0,62 & $0,33-1,17$ \\
\hline$[60-70[$ & 35 & 37 & 4,36 & S & 1,81 & $1,04-3,16$ \\
\hline$[70-80[$ & 9 & 34 & 30,92 & HS & 7,67 & $3,47-16,94$ \\
\hline$\geq 80$ & 3 & 10 & 8,35 & VS & 5,75 & 1,54-21,51 \\
\hline Total & 141 & 99 & & & & \\
\hline \multicolumn{7}{|l|}{ Toxic habits } \\
\hline Alcohol & 1 & 1 & 0,02 & NS & 1,25 & $0,08-20,69$ \\
\hline Tobacco & 20 & 18 & 1,66 & NS & 1,75 & $0,75-4,11$ \\
\hline Alcohol +Tobacco & 21 & 13 & 0,94 & NS & 0,64 & $0,26-1,56$ \\
\hline Non-Steroidal Anti-Inflammatories & 3 & 5 & 1,08 & NS & 2,19 & $0,49-9,85$ \\
\hline Plant & 0 & 1 & 1,26 & NS & - & - \\
\hline Total & 45 & 37 & & & & \\
\hline \multicolumn{7}{|l|}{ H.pylori } \\
\hline $\mathrm{Hp}+$ & 26 & 18 & 1,33 & NS & 0,68 & $0,35-1,32$ \\
\hline Hp- & 97 & 99 & & & 1,47 & $0,76-2,85$ \\
\hline Total & 123 & 117 & & & & \\
\hline
\end{tabular}

The studied variables include Sex, age group, toxic habits, presence of helicobacter pylori (Hp +), and absence of helicobacter pylori (Hp-). The sex of the patients did not have a significant association with the death. Patients over the age of 60 have shown a risk of progression to death. This risk is 
accentuated in the older group of $60-70$ years $(\mathrm{OR}=7.67$ to $95 \%$ CI [3.4716.94]), as well as those aged 80 years and above (OR $=5.75$ at $\mathrm{CI}$ at $95 \%$ [1.54-21.51]). Adenocarcinomatous patients with toxic habits such as alcohol, tobacco, alcohol + tobacco, plants, and Non-Steroidal Anti-Inflammatories did not mount a significant association with the development of the disease. According to the results of Table 2, no risk was shown in the absence or presence of the Hp bacteria.

On the other hand, we have studied the influence of $\mathrm{Hp}$ on the localization of gastric adenocarcinoma (Table 3). According to the results of Table 3, there is no significant difference between the presence or absence of the bacterium Hp and the different localizations studied.

Table 3. Distribution of odds ratio for the location according to the presence or absence of $\mathrm{Hp}$

\begin{tabular}{|c|c|c|c|c|c|}
\hline Localization & Antral & $x^{2}$ & $\mathbf{P}$ & OR & CI to $95 \%$ \\
\hline n (Hр+) & 29 & 2,78 & 0,09 & 1,78 & $0,9-3,52$ \\
\hline n (Hр-) & 102 & & & 0,56 & $0,28-1,11$ \\
\hline \multicolumn{6}{|c|}{ Cardia } \\
\hline n (Hp+) & 1 & 4,34 & 0,03 & 0,15 & $0,02-1,15$ \\
\hline n (Hp-) & 26 & & & 6,57 & $0,86-49,8$ \\
\hline \multicolumn{6}{|c|}{ Fundus } \\
\hline n (Hp+) & 9 & 0,02 & 0,89 & 0,94 & $0,42-2,11$ \\
\hline n (Hp-) & 42 & & & 1,06 & $0,47-2,38$ \\
\hline \multicolumn{6}{|c|}{ Pangastrique } \\
\hline n (Hp+) & 5 & 0,12 & 0,73 & 0,83 & $0,30-2,32$ \\
\hline n (Hp-) & 26 & & & 1,19 & $0,43-3,30$ \\
\hline
\end{tabular}

$\mathrm{Hp+:}$ presence of helicobacter pylori, Hp- : absence of helicobacter pylori

\section{Discussion}

Stomach cancer is essentially represented by gastric adenocarcinomas, which remains one of the top ten global causes of mortality with a prognosis that is pejorative. They are about $90 \%$ of cases where adenocarcinoma was developed at the expense of the gastric epithelium. Other tumors are lymphoma (5\%), neuroendocrine tumors, and stromal tumors (Gallo \& Cha, 2006). Gastric adenocarcinoma remains one of the top 10 global causes of cancer-related mortality due to poor prognosis (Aparicio et al., 2004).

It is a cancer with variable incidence worldwide, the highest in East Asia (Japan, China and Korea), and 102,040 new cases were reported in Japan in 2008 (Yingsong et al., 2011). A total of 240 cases of ADK were collected during the study period, with an annual average of 22 cases / year, which represents $77 \%$ of all gastric cancers identified. In other works, the ADK represented a frequency of 70.1 to 100\% (Ayite et al., 2004; Biffi et al., 2010), which confirms our results. During the study period, 99 cases of death were recorded at a rate of $41 \%$. This result is similar with the literature (Bouglouga et al., 2011) which is of the order of $40 \%$. The average age of patients is $59 \pm$ 
0.93 years, with a minimum age of 22 years and a maximum age of 90 years, which seems consistent with other publications (Luis et al., 2007; Ilter et al., 2010).

The frequency of this cancerous pathology is twice as high in males $(63.77 \%)$ as in females, with a highly significant difference $(\mathrm{p}<0.001)$ according to our study. This situation is similar to other results whose sex ratio was M F = 2 (Aparicio et al., 2004).

High male risk is related to more frequent toxic habits in men and, in the majority of cases, it is related to smoking and / or alcoholism, occupational exposure, and environmental and carcinogenic substances (Neuberger et al., 2006; Martinez et al., 2005).

According to our study, the frequency of the association of Helicobacter pylori with the presence of gastric adenocarcinomas is $18 \%$. In other studies, the frequency of Helicobacter pylori is about $15 \%$ (Enneddam, 2008).

Several environmental factors, genetic, and a number of conditions have been incriminated as etiopathogenic factors in the occurrence of gastric cancer.

Smoking has been shown to induce gastric cancer and was classified by the International Cancer Research Agency as a group 1 gastric carcinogen. In our study, no significant difference was found between smoking and the occurrence of $\operatorname{ADK}(\mathrm{p}>0.05)$, which is consistent with a German study (Bornschein et al., 2011). Similarly, nonsteroidal anti-inflammatory drugs have no significant effect on the development of ADK according to our study. In other work, these anti-inflammatories have an effect on carcinogenicity (Glehen et al., 2000).

On the other hand, in our study, alcohol represents $3 \%$ of all toxic habits. In other publications, the concept of alcoholism was found in $2.79 \%$ of patients (Salmi, 1995). This discrepancy is due to the number of cases collected from one study to another. However, in all cases, studies have shown that there is no obvious relationship in the occurrence of gastric ADK and alcohol consumption (Aparicio et al., 2004), which is consistent with our results. The gastric cancers sit more frequently in the zones of mucous junction in the prepyloric region, in the antrum, and in the small curvature. The antral location represents $60 \%$. This percentage matches that of our study which was $55 \%$. In other works, it is respectively 50.3\%, 50\%, and 52\% (Glehenal, 2000; Marcato, 2007; Nakamura et al., 2002).

\section{Conclusion}

Gastric cancer is a real health problem. Hence, there is the need to organize information and education campaigns in order to encourage people 
to consult early on functional signs and to treat patients early in order to control the disease and avoid deadly results.

\section{References:}

1. Aparicio, T., Yacoub, M., Karila-Cohen, P., \& René, E. (2004). Adénocarcinome gastrique : notions fondamentales, diagnostic et traitement, EMC chirurgie 1(1):1-84.

2. Ayite, A.E., Adodo, K., Dosseh, E., Abita, T., \& Ocloo, A. (2004). Prise en charge du cancer primitif de l'estomac au CHU de Lome. A propos de 63 cas. Tunis Med ; 82(8):747-52.

3. Bachir, M., Allem, R., Benejat, L., Tifrit, A., Medjekane, M., Drici, A. E. M., ... \& Douidi, K.T. (2018). Molecular detection of mutations involved in Helicobacter pylori antibiotic resistance in Algeria. Journal of Antimicrobial Chemotherapy.

4. Biffi, R., Nicolo, F., \& Luca, F. (2010). Resultats de la chirurgie après chimiotherapie neoadjuvante à base de docetaxel dans le cancer gastrique localement avance. World journal gastroentel; 21(17): 868874.

5. Bornschein, J., Rokkas, T., Selgrad, M., Malfertheiner, P. (2011). Gastric Cancer: Clinical Aspects, Epidemiology and Molecular Background. Helicobacter ; 16 (Suppl 1):45-52.

6. Bouglouga, O., Bagny, A., Djibril, M.A., M'ba, F., Redah, D. \& Agbetra, A. (2011). Particularités diagnostiques et évolutives du cancer gastrique en milieu Africain Noir a propos de 21 cas. Journal de la Recherche Scientifique de l'Universite de Lome, 13(2), 11-18.

7. Carl-McGrath, S., Ebert, M., \& Röcken, C. (2008). Gastric adenocarcinoma: epidemiology, pathology and pathogenesis. Cancer Therapy; 6:877-93.

8. Correa, P. \& Piazuelo, MB. (2012). The gastric precancerous cascade. J Dig Dis; 13:2-9.

9. Enneddam, H. (2008). Epidemiologie des cancers de l'estomac dans la région de Marrakech. Thèse $\mathrm{N}^{\circ} 23$.

10. Ferlay, J., Soerjomataram, I., Ervik, M.,....Globocan (2012). Cancer Incidence and Mortality Worldwide: IARC Cancer Base 2013. Available online: http://globocan.iarc.fr.

11. Fock, KM. (2014). Review article: the epidemiology and prevention of gastric cancer. Aliment Pharmacol Ther; 40:250-60.

12. Gallo, A. \& CHA, C. (2006). Updates on Esophageal and Gastric cancers. World J Gastroenterol; 12(20) :3237-3247.

13. Glehen, O., Traverse-glehen, A., Peyrat, P., François, Y., Gerard, J P., Vignal, J. \& Gilly, NF. (2000). L'adénocarcinome de l'estomac. 
Evolution du traitement chirurgical dans une série de 350 cas. Annales de chirurgie, 8(12)5:744-751

14. Luis, F., Mendez-cruz, G., \& Hernandez-Ramos, R. (2007). L'expérience de la morbidité opératoire après chirurgie palliative chez les patients souffrant de cancer gastrique,Japanese Gastric cancer ; 10 :215-220.

15. Malfertheiner, P., Megraud, F., O'morain, C.A., Atherton, J., Axon, A. T., Bazzoli, F., \& El-Omar, E.M. (2012). Management of Helicobacter pylori infection the Maastricht IV/Florence consensus report. Gut, 61(5), 646-664.

16. Marcato, N., Slim, K., Darcha, C., \& Bommelaer, G. (2007). Tumeurs gastriques. Traité de gastroentérologie, 2ème édition, chapitre 31, P 374-384.

17. Martel, C., Ferlay, J., Franceschi, S. et al. (2012). Global burden of cancers attributable to infections in 2008: a review and synthetic analysis. The Lancet Oncology 13: 607-615.

18. Nakamura, S., Matsumoto, T., Kobori, Y., \& Ida, M. (2002). Impact of Helicobacter Pylori infection and mucosal atrophy on gastric lesions in patients with familial adenomatous plyposis. Gut; 51:485-489.

19. Neuberger, J.S., Mahnken, J.D., Mayo, M.S., \& Field R.W. (2006). Risk factors for lung cancer in Iowa women: Implications for prevention, Cancer Detection and Prevention, no. 30, pp. 158-167.

20. Salmi, EJ. (1995). Profil épidémiologique des cancers gastriques (A propos de215 cas). Thèse méd. Casablanca $\mathrm{N}^{\circ} 166$.

21. Yingsong, L., Junko, U., \& Shogo, K. (2011). Comparative epidemiology of gastric cancer between Japan and China. World J Gastroenterol. 21; 17(39):4421-4428. 